\title{
42. INTERRELATIONSHIPS BETWEEN SEDIMENT COMPOSITION, COMPACTION, PORE SPACE, AND SHRINKAGE, LEG 75, HOLE 532A ${ }^{1}$
}

\author{
Andreas Wetzel, Geologisches Institut der Universität, Sigwartstraße 10, D 7400 Tübingen, \\ Federal Republic of Germany
}

\begin{abstract}
Orientation and geometry of pores as well as sediment compressibility can be approximated by determining the shrinkage behavior of standardized samples. The sections investigated show that these measurements are influenced by changing sediment composition. This is also well documented by the relationship between void ratio and overburden pressure. Median pore-diameter calculations clearly reflect both sediment composition and compaction.
\end{abstract}

\section{INTRODUCTION}

Compaction of sediments strongly modifies volume and geometry of pores. For seafloor deposits, these characteristics depend mainly on sediment composition, which also influences the resistance of sediments to compaction. Since simple measurements are lacking, consolidation test procedures are used to evaluate sediment compressibility (see chapter by the Geotechnical Consortium, this volume). The relationship between sediment volume and pressure during consolidation is analogous to that between water content and volume of sample during drying (Hartge, 1978). Thus, this study attempts to use shrinkage and related measurements as simple indicators of volume and nature of pore space and sediment compressibility.

Shrinkage can be easily determined by measuring the height and diameter of a dried cylinder sample which has been taken primarily for porosity and other determinations of water-saturated sediments.

\section{METHODS}

Bulk density, water content, porosity, and void ratio were determined by standard laboratory methods (Schultze and Muhs, 1967). A cylinder sample of known volume $\left(V_{o}\right)$ was taken perpendicular to the "bedding," weighed (wet weight, $G_{o}$ ) and dried for 24 hours at $110^{\circ} \mathrm{C}$. Then the dry weight $\left(G_{d}\right)$, height, and diameter (for calculation of dry volume, $V_{d}$ ) were measured (accuracy of each measurement is $\pm 1 \%$; for $V_{d} \pm 2 \%$ ).

For porosity and void ratio determinations, it was assumed that the sediment was water saturated. However, expanding gas may have affected the measurements.

The water content, wet-bulk density, porosity, and void ratio of Hole 532A are discussed in some detail in the chapter by the Geotechnical Consortium. Therefore, these data are only listed in Table 1.

Shrinkage $(S h)$ is the loss of volume expressed as a percentage of the original:

$$
S h=\frac{V_{o}-V_{d}}{\mathrm{~V}_{\mathrm{o}}} \times 100(\%)
$$

\footnotetext{
${ }^{1}$ Hay, W. W., Sibuet, J.-C., et al., Init. Repts. DSDP, 75: Washington (U.S. Govt. Printing Office).
}

Carbonate content was determined by dissolving the carbonate in $\mathrm{HCl}$ and then measuring $\mathrm{HCl}$ consumption by titration with $\mathrm{NaOH}$. Phenolphthalein was used as an indicator.

For grain-size analysis, five size fractions were determined: $>63 \mu \mathrm{m}, 63-20 \mu \mathrm{m}, 20-6 \mu \mathrm{m}, 6-2 \mu \mathrm{m}$, and $<2 \mu \mathrm{m}$. After wet-sieving $(63 \mu \mathrm{m})$, the finer-grained part of the sample was desalted and dispersed by $\mathrm{NH}_{4} \mathrm{OH}$. The grain fractions were analyzed using Atterberg settling tubes (Lippmann, 1953).

The area of the internal surfaces was determined using Ströhlein Areameter II equipment; at the temperature of fluid nitrogen, $\mathrm{N}_{2}$ adsorption at the internal surfaces of the water-free samples was measured.

Scanning electron microscope (SEM) studies were carried out on some samples which were vacuum freeze-dried.

\section{AREA OF INTERNAL SURFACES AND RELATED MEASUREMENTS}

The area of the internal surfaces varies widely within those sections investigated. There exists no clear relationship to the $<2 \mu$ m sediment fraction as had been expected (Heling, 1970). This may be the result of (1) variations in the mineralogical composition and grain-size distribution of the clay fraction, (2) changing biogeneous constituents (foraminifers-diatoms-nannofossils), and (3) the content (and composition?) of organic matter (Schachtschabel et al., 1976). However, these parameters have not yet been determined for Hole 532A.

In this study, the area of internal surfaces is only used for calculation of the median pore diameter.

\section{Median Pore Diameter}

Theoretically, a given sediment porosity can result from either a small number of large pores or a large number of small pores. In the first case, the sediment has a relatively small area of internal surfaces, whereas in the latter case, it has a large area of internal surfaces. The area of internal surface varies inversely with pore size and can be derived from the relationship formulated by Hudec (1978):

Area of internal surfaces $\left(\mathrm{m}^{2} \mathrm{~g}^{-1}\right)=$

$\underline{\text { Porosity }\left(\mathrm{cm}^{3} \mathrm{~g}^{-1}\right) \times \text { pore area }\left(\mathrm{cm}^{2}\right)}$ Pore volume $\left(\mathrm{cm}^{3}\right)$ 
Thus, for the simplified case of spherical pores the pore diameter can be calculated after the formula of Hudec (1978) by the following equation:

Median pore diameter $(\mathrm{cm})=$

$$
\frac{\text { Porosity }\left(\mathrm{cm}^{3} \mathrm{~g}^{-1}\right) \times 6}{\text { Area of internal surfaces }\left(\mathrm{m}^{2} \mathrm{~g}^{-1}\right)}
$$

Mean pore diameter (Table 1, Fig. 1) has been calculated in this way.

The trend lines in Figure 1 show a decrease in median pore diameter with increasing core depth. However, in this general trend the influence of compaction cannot be determined because it is coincident with changing sedi- ment composition - that is (1) the dominant biogeneous constituents decrease in size from lithologic Subunit 1a to $1 c$ (foraminifer tests-diatom frustules-nannofossils), and (2) the frequency of foraminifers and diatoms gradually decreases toward the lower boundary of Subunits $1 \mathrm{a}$ and $1 \mathrm{~b}$, respectively. In Subunit $1 \mathrm{a}$ the decrease in median pore diameter reflects the decrease in foraminifer content rather than compaction. The scattered data also support this assumption.

In Subunit $1 \mathrm{~b}$, the median pore diameter is strongly influenced by varying diatom content. A decrease in median pore diameter as a result of compaction cannot be expected for diatomaceous oozes at such a shallow burial depth (Hamilton, 1976).

\begin{tabular}{|c|c|c|c|c|c|c|c|c|c|c|c|c|c|c|}
\hline \multirow{2}{*}{$\begin{array}{c}\begin{array}{c}\text { Core- } \\
\text { Section } \\
\text { (level in cm) }\end{array} \\
\end{array}$} & \multirow{2}{*}{$\begin{array}{l}\text { Depth } \\
\text { in core } \\
(\mathrm{cm})\end{array}$} & \multirow{2}{*}{$\begin{array}{c}\text { Water } \\
\text { content } \\
(\%)\end{array}$} & \multirow{2}{*}{$\begin{array}{l}\text { Wet-bulk } \\
\text { density } \\
\left(\mathrm{g} / \mathrm{cm}^{3}\right)\end{array}$} & \multirow[b]{2}{*}{ Porosity } & \multirow[b]{2}{*}{$\begin{array}{l}\text { Void } \\
\text { ratio }\end{array}$} & \multirow{2}{*}{$\begin{array}{c}\text { Shrinkage } \\
(\%)\end{array}$} & \multirow{2}{*}{$\begin{array}{c}\text { Carbonate } \\
\text { content } \\
(\%)\end{array}$} & \multirow{2}{*}{$\begin{array}{l}\text { Area of } \\
\text { internal } \\
\text { surface } \\
\left(\mathrm{m}^{2} / \mathrm{g}\right)\end{array}$} & \multirow{2}{*}{$\begin{array}{l}\text { Median } \\
\text { pore } \\
\text { radius } \\
(\mu \mathrm{m})\end{array}$} & \multicolumn{5}{|c|}{ Grain size distribution $(\mu \mathrm{m})$} \\
\hline & & & & & & & & & & $\begin{array}{l}<2 \\
(\%)\end{array}$ & $\begin{array}{l}2-6 \\
(\%)\end{array}$ & $\begin{array}{l}6-20 \\
(\%)\end{array}$ & $\begin{array}{c}20-63 \\
(\%)\end{array}$ & $\begin{array}{l}>63 \\
(\%)\end{array}$ \\
\hline $1-1$ & 17 & 127 & 1.39 & 0.78 & 3.50 & 50.0 & 71 & 9.2 & 0.254 & 18.0 & 12.0 & 19.4 & 30.1 & 20.5 \\
\hline $1-2$ & 286 & 135 & 1.35 & 0.78 & 3.46 & 47.8 & 48 & 9.6 & 0.242 & 48.4 & 11.3 & 11.7 & 13.2 & 15.4 \\
\hline $2-1$ & 476 & 109 & 1.43 & 0.74 & 2.90 & 44.4 & 62 & 9.7 & 0.230 & 27.5 & 17.2 & 20.4 & 19.9 & 14.9 \\
\hline $2-2$ & 627 & 108 & 1.42 & 0.73 & 2.74 & 47.6 & 55 & 12.3 & 0.179 & 36.0 & 9.9 & 12.8 & 16.2 & 25.1 \\
\hline $3-1$ & 876 & 117 & 1.41 & 0.76 & 3.15 & 56.7 & 46 & 10.5 & 0.217 & 28.5 & 14.8 & 18.4 & 20.3 & 17.9 \\
\hline $3-2$ & 1076 & 110 & 1.42 & 0.75 & 2.94 & 50.0 & 46 & 12.6 & 0.178 & 48.0 & 15.7 & 16.7 & 11.0 & 8.6 \\
\hline $4-1$ & 1351 & 87 & 1.48 & 0.69 & 2.21 & 53.8 & 76 & 9.8 & 0.211 & 54.0 & 14.9 & 11.5 & 11.8 & 7.7 \\
\hline $4-2$ & 1441 & 91 & 1.48 & 0.70 & 2.37 & 57.1 & 71 & 11.0 & 0.192 & 49.4 & 3.3 & 13.2 & 11.9 & 22.3 \\
\hline $5-1$ & 1756 & 85 & 1.50 & 0.69 & 2.21 & 50.0 & 62 & 11.0 & 0.188 & 51.4 & 11.9 & 12.3 & 18.4 & 6.0 \\
\hline 6-1 & 2180 & 109 & 1.41 & 0.74 & 2.81 & 48.5 & 49 & 13.6 & 0.163 & 35.0 & 12.8 & 15.7 & 18.2 & 18.3 \\
\hline $6-3$ & 2352 & 108 & 1.37 & 0.71 & 2.50 & 45.0 & 51 & 15.2 & 0.141 & 43.9 & 17.6 & 15.5 & 12.3 & 10.7 \\
\hline 7.2 & 2716 & 119 & 1.31 & 0.71 & 2.49 & 41.7 & 67 & 14.1 & 0.152 & 37.7 & 23.9 & 16.4 & 8.8 & 13.2 \\
\hline $8-1$ & 3026 & 95 & 1.48 & 0.72 & 2.58 & 57.1 & 63 & 10.7 & 0.202 & 36.2 & 19.8 & 16.5 & 17.5 & 9.9 \\
\hline $8-1$ & 3031 & 104 & 1.38 & 0.70 & 2.37 & 50.0 & 47 & 14.8 & 0.143 & 36.2 & 19.8 & 16.5 & 17.5 & 9.9 \\
\hline $9-1$ & 3438 & 107 & 1.39 & 0.72 & 2.55 & 50.0 & 48 & 15.0 & 0.144 & 37.4 & 14.8 & 11.0 & 15.8 & 21.0 \\
\hline $10-2$ & 4026 & 102 & 1.42 & 0.72 & 2.54 & 40.0 & 60 & 19.6 & 0.110 & 29.5 & 14.2 & 17.1 & 22.6 & 16.6 \\
\hline $11-1$ & 4331 & 95 & 1.47 & 0.72 & 2.54 & 54.8 & 46 & 20.0 & 0.108 & 32.0 & 16.6 & 14.7 & 18.8 & 17.9 \\
\hline $11-2$ & 4466 & 94 & 1.45 & 0.70 & 2.34 & 59.1 & 56 & 18.2 & 0.115 & 36.4 & 19.0 & 17.2 & 15.4 & 12.0 \\
\hline $11-3$ & 4616 & 103 & 1.40 & 0.71 & 2.47 & 59.3 & 28 & 20.8 & 0.103 & 29.7 & 18.0 & 13.0 & 11.6 & 27.7 \\
\hline $12-3$ & 5051 & 106 & 1.39 & 0.72 & 2.54 & 50.0 & 24 & 22.6 & 0.095 & 46.5 & 19.1 & 18.3 & 12.4 & 3.7 \\
\hline $13-3$ & 5496 & 124 & 1.31 & 0.72 & 2.61 & 55.6 & 26 & 21.2 & 0.102 & 38.6 & 6.2 & 23.6 & 13.4 & 5.2 \\
\hline $14-1$ & 5651 & 145 & 1.36 & 0.80 & 4.05 & 63.6 & 35 & 19.0 & 0.127 & 45.5 & 17.3 & 19.2 & 10.5 & 7.5 \\
\hline $14-1$ & 5651 & 133 & 1.41 & 0.80 & 4.10 & 62.5 & 45 & 19.0 & 0.127 & 45.5 & 17.3 & 19.2 & 10.5 & 7.5 \\
\hline $15-1$ & 6121 & 142 & 1.35 & 0.79 & 3.81 & 62.5 & 35 & 20.0 & 0.119 & 53.3 & 19.0 & 15.3 & 7.6 & 4.8 \\
\hline $16-2$ & 6666 & 98 & 1.34 & 0.67 & 2.00 & 47.1 & 40 & 20.0 & 0.100 & 40.9 & 20.2 & 20.0 & 14.5 & 4.4 \\
\hline $17-1$ & 7018 & 132 & 1.36 & 0.77 & 3.42 & 52.9 & 42 & 20.0 & 0.116 & 59.2 & 12.4 & 12.9 & 9.4 & 6.2 \\
\hline 17.2 & 7371 & 116 & 1.34 & 0.72 & 2.61 & 42.9 & 25 & 19.8 & 0.110 & 40.1 & 22.7 & 20.2 & 10.3 & 6.7 \\
\hline $18-2$ & 7606 & 104 & 1.36 & 0.69 & 2.28 & 56.5 & 24 & 19.4 & 0.107 & 39.6 & 24.3 & 18.2 & 11.0 & 6.8 \\
\hline $18-3$ & 7686 & 136 & 1.28 & 0.74 & 2.85 & 54.5 & 11 & 22.8 & 0.097 & 31.8 & 26.5 & 28.5 & 9.5 & 3.6 \\
\hline $19-3$ & 8152 & 117 & 1.35 & 0.73 & 2.69 & 57.1 & 36 & 20.9 & 0.105 & 55.1 & 19.4 & 16.3 & 6.8 & 2.4 \\
\hline $20-3$ & 8631 & 108 & 1.39 & 0.72 & 2.54 & 54.5 & 27 & 22.0 & 0.098 & 35.4 & 22.4 & 17.8 & 6.9 & 17.5 \\
\hline $21-2$ & 8986 & 84 & 1.48 & 0.68 & 2.11 & 52.4 & 38 & 22.8 & 0.089 & 32.4 & 18.2 & 26.4 & 15.9 & 7.1 \\
\hline $21-3$ & 9056 & 80 & 1.50 & 0.67 & 2.00 & 53.8 & 60 & 19.0 & 0.105 & 53.7 & 16.8 & 12.7 & 10.4 & 6.4 \\
\hline $22-3$ & 9451 & 143 & 1.31 & 0.77 & 3.42 & 60.0 & 52 & 20.4 & 0.114 & 51.7 & 24.0 & 16.7 & 4.8 & 2.7 \\
\hline 23-3 & 9891 & 67 & 1.54 & 0.62 & 1.60 & 58.3 & 50 & 13.2 & 0.140 & 34.2 & 18.0 & 29.7 & 11.6 & 6.5 \\
\hline $24-3$ & 10331 & 103 & 1.37 & 0.69 & 2.28 & 30.0 & 51 & 21.0 & 0.099 & 39.8 & 25.8 & 22.6 & 6.8 & 5.0 \\
\hline $26-1$ & 11021 & 89 & 1.45 & 0.68 & 2.16 & 58.3 & 49 & 16.9 & 0.121 & 38.0 & 32.2 & 19.7 & 7.2 & 2.8 \\
\hline $28-1$ & 11852 & 94 & 1.44 & 0.69 & 2.28 & 57.1 & 37 & 22.3 & 0.093 & 39.6 & 23.4 & 22.9 & 9.9 & 4.1 \\
\hline 29-1 & 12252 & 85 & 1.37 & 0.63 & 1.72 & 48.0 & 25 & 17.3 & 0.110 & 37.1 & 25.2 & 24.2 & 11.3 & 3.2 \\
\hline $29-2$ & 12442 & 77 & 1.53 & 0.67 & 2.00 & 53.3 & 51 & 21.1 & 0.095 & 36.6 & 25.5 & 18.6 & 7.5 & 11.8 \\
\hline $30-2$ & 12842 & 78 & 1.50 & 0.66 & 1.90 & 54.5 & 36 & 21.7 & 0.091 & 34.9 & 17.0 & 21.7 & 5.7 & 26.7 \\
\hline $30-3$ & 12982 & 71 & 1.55 & 0.64 & 1.81 & 50.0 & 49 & 23.0 & 0.084 & 49.1 & 23.1 & 17.3 & 7.7 & 2.8 \\
\hline $31-1$ & 13222 & 72 & 1.55 & 0.65 & 1.85 & 55.0 & 40 & 19.0 & 0.103 & 37.1 & 23.8 & 23.6 & 12.0 & 3.5 \\
\hline $32-1$ & 13592 & 75 & 1.54 & 0.66 & 1.95 & 46.7 & 46 & 21.8 & 0.091 & 47.6 & 24.1 & 17.6 & 6.6 & 4.0 \\
\hline $32-2$ & 13798 & 62 & 1.61 & 0.62 & 1.60 & 53.8 & 49 & 23.7 & 0.078 & 43.2 & 19.8 & 18.1 & 9.7 & 9.2 \\
\hline 33-1 & 14052 & 86 & 1.45 & 0.67 & 2.05 & 44.4 & 44 & 22.5 & 0.090 & 42.1 & 23.4 & 21.6 & 9.9 & 3.7 \\
\hline $34-1$ & 14498 & 68 & 1.58 & 0.64 & 1.77 & 52.9 & 46 & 18.2 & 0.105 & 34.3 & 22.1 & 25.6 & 14.3 & 3.7 \\
\hline $34-3$ & 14727 & 65 & 1.60 & 0.63 & 1.68 & 53.9 & 52 & 20.9 & 0.090 & 50.7 & 22.0 & 14.7 & 9.3 & 3.4 \\
\hline $36-1$ & 15373 & 68 & 1.61 & 0.66 & 1.90 & 56.3 & 47 & 18.4 & 0.107 & 46.9 & 17.6 & 16.7 & 13.1 & 5.9 \\
\hline $36-3$ & 15647 & 58 & 1.64 & 0.60 & 1.53 & 53.8 & 50 & 19.2 & 0.094 & 47.5 & 18.9 & 18.3 & 10.7 & 4.6 \\
\hline $38-2$ & 16357 & 58 & 1.66 & 0.61 & 1.57 & 50.0 & 53 & 20.4 & 0.090 & 39.7 & 21.3 & 20.0 & 13.4 & 5.6 \\
\hline $40-3$ & 17127 & 63 & 1.62 & 0.62 & 1.64 & 46.7 & 53 & 22.7 & 0.082 & 49.1 & 23.1 & 15.2 & 9.0 & 3.6 \\
\hline $41-3$ & 17601 & 65 & 1.60 & 0.63 & 1.68 & 53.3 & 35 & 19.1 & 0.099 & 47.1 & 23.8 & 16.6 & 10.2 & 2.2 \\
\hline $42-2$ & 17942 & 30 & 1.62 & 0.61 & 1.57 & 55.6 & 46 & 23.1 & 0.079 & 41.8 & 24.8 & 17.8 & 13.2 & 2.4 \\
\hline $44-2$ & 18588 & 56 & 1.66 & 0.59 & 1.46 & 53.8 & 53 & 19.6 & 0.091 & 46.5 & 21.7 & 19.4 & 9.4 & 2.9 \\
\hline $47-2$ & 13751 & 55 & 1.67 & 0.58 & 1.39 & 58.3 & 59 & 20.8 & 0.084 & 53.2 & 24.4 & 15.1 & 5.3 & 2.0 \\
\hline $47-3$ & 19872 & 50 & 1.70 & 0.57 & 1.33 & 45.5 & 54 & 22.8 & 0.075 & 54.5 & 19.4 & 18.1 & 5.4 & 2.6 \\
\hline
\end{tabular}

Table 1. Sediment data, Hole 532A. 


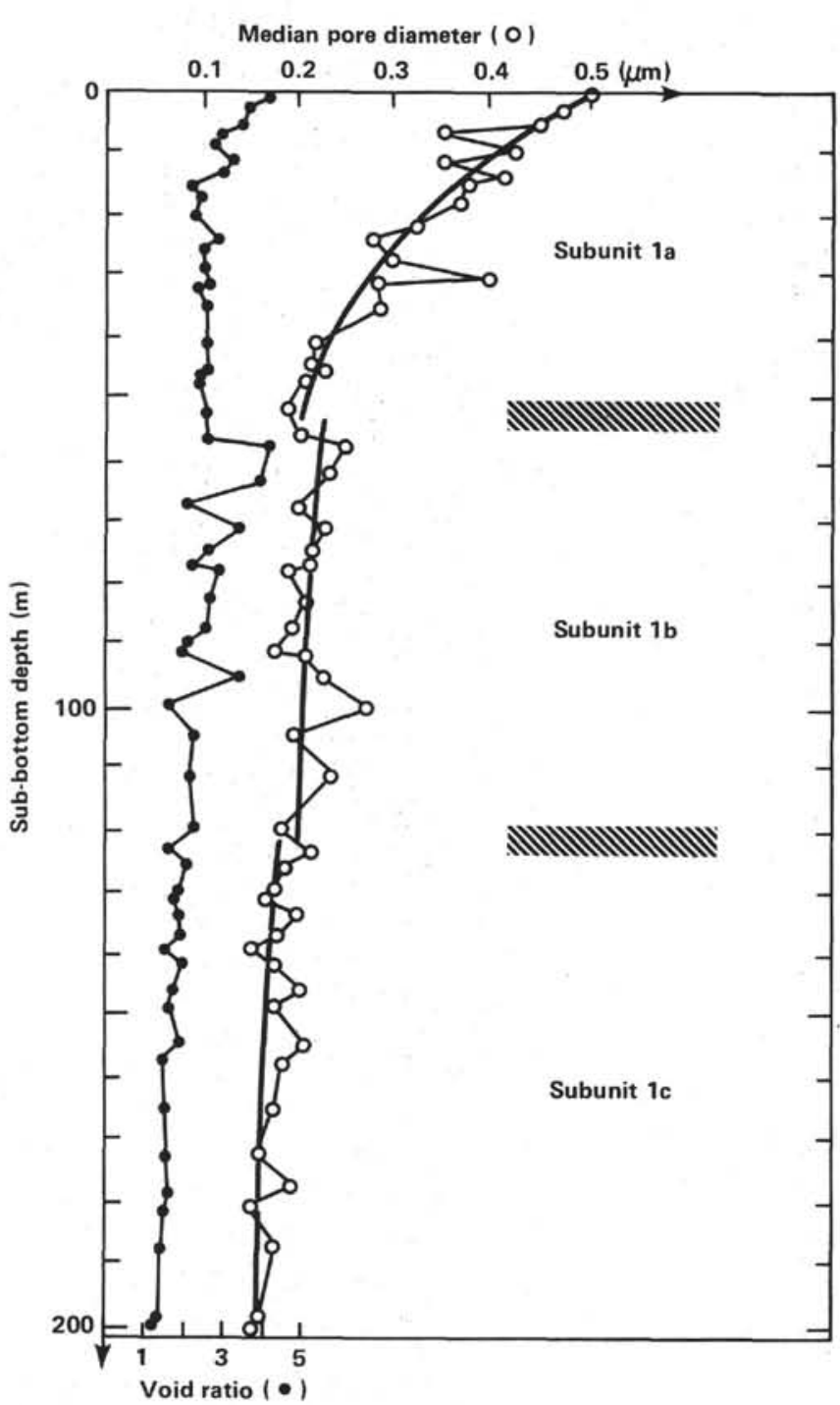

Figure 1. Median pore diameters calculated after Hudec (1978). Trend lines have been computed for each lithologic subunit. For Subunits $1 \mathrm{a}$ and $1 \mathrm{c}$ they follow an $e-\log$ curve, and for $1 \mathrm{~b}$ a straight line. The trend line for $1 \mathrm{a}$ is strongly influenced by the decreasing foraminifer content. Scattering of data results from variations in sediment composition.

Subunit $1 \mathrm{c}$ is less influenced by varying sediment composition; the mean value line follows an $e$-log curve, and the data points better fit the line.

\section{PORE SYSTEM}

A dual pore system has been found that is also known from other sediments (Reimers, 1982). It consists of (1) macropores $>2 \mu \mathrm{m}$ and (2) micropores $<2 \mu \mathrm{m}$ in diameter. Macropores were measured in SEM photographsmicropores only to a lesser extent. Most support for the micropore system is provided by calculation of median pore diameter. Macropores are found primarily in combination with biogeneous components: within or next to foraminiferal tests or diatom frustules.

During compaction the intraparticle pores within biogenic tests are filled in the upper tens of meters, whereas wide pores supported by large grains slowly decrease in frequency and size; in near-surface sediments 30 pores of $>2 \mu \mathrm{m}$ diameter have been counted per $1,000 \mu \mathrm{m}^{2}$ area of SEM photos (maximum diameter $40-50 \mu \mathrm{m}=$ $\sim 15 \%$ ), whereas at about 200 -m depth only 5 pores of $>2 \mu \mathrm{m}$ diameter were found (maximum diameter 5-15 $\mu \mathrm{m}=\sim 5 \%)$.

\section{SHRINKAGE}

Shrinkage is caused by suction pressure within the pores. This results from capillary forces occurring when pore water is lost during drying. Capillary forces depend principally on pore width and are therefore not directly affected by sediment composition (Hartge, 1978). There is normally no limit for suction pressure within the pore system, because capillary forces increase during drying and, furthermore, water has a high tensile strength $\left(10,550 \mathrm{~N} \mathrm{~cm}^{-2}, 20^{\circ} \mathrm{C}\right.$; Brinch Hansen and Lundgren, 1960). However, at a certain water content-the socalled shrinkage limit - the sample maintains a constant volume even if the water content decreases further; the area within the water menisci that is affected by high suction pressure is too small to deform the sample.

Shrinkage acts in a way similar to the application of external pressure, and can, therefore, be compared with the result of an effective overburden pressure (Einsele, 1982). Properties such as void ratio or median pore diameter depend after total drying on the composition of the sediment. Thus, shrinkage values may provide valuable information about sediment composition and its early diagenesis. The loss of volume by shrinkage is controlled by several factors: (1) initial water content and porosity, (2) texture and fabric (microstructure) of sediment forming the pore space, (3) sediment composition, and (4) bond strength between particles, which prevents deformation by negative pore pressure or suction pressure (Einsele, 1982).

Shrinkage varies widely within Hole $532 \mathrm{~A}$. With increasing carbonate content, shrinkage values decrease (Fig. 2). Thus, carbonate seems to stabilize sediment microstructure. However, there exists no clear quantitative relationship between carbonate content and shrinkage (Fig. 3). This may be a result of the varying amount of organic matter (Pusch, 1973) and changing sediment composition. It can be shown that shrinkage is controlled by carbonate type; with the same carbonate content, foraminifer-rich sediments shrank more than did those with nannofossils as the major carbonate constituent (Fig. 3). In sediments rich in foraminifers, the carbonate is concentrated in a relatively small number of grains, whereas nannofossils may be finely dispersed. Thus, the latter are more effective in stabilizing grain structure (Fig. 4).

Shrinkage can reveal various aspects of compressibility and for this reason some properties, such as void ratio, median pore diameter, and bulk density of the shrunken samples, are compared with those of the fresh sediment. Interpolation of moving-average calculations indicate a reduction in void ratio and median pore diameter as well as an increase in bulk density by shrinkage that corresponds to an additional overload. This has been estimated in the following way: Each of these 


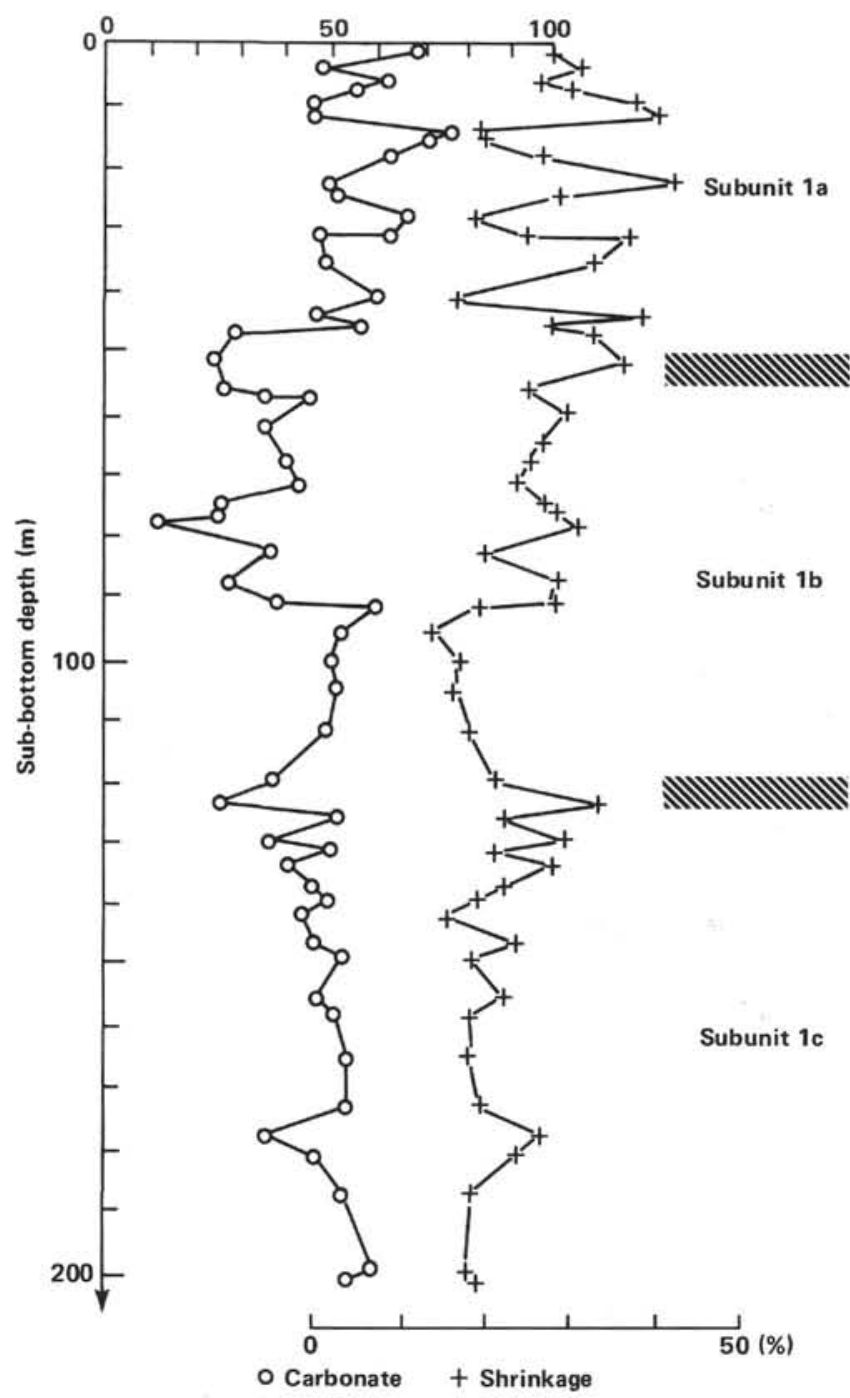

Figure 2. Carbonate content and shrinkage showing a generally inverse relationship. Generally, at the same carbonate content, shrinkage decreases downward within each lithologic subunit.

properties tends to reach a limiting value, drawn for void ratio in Figure 5. For mean sediment composition for Subunit 1a, a void ratio value of 1.5 has been determined; for $1 \mathrm{~b}, 1.8$; and for $1 \mathrm{c}, 1.0$. Interpolating trend lines from the fresh sediment, these values correspond to a burial depth (overburden pressure) of $170 \mathrm{~m}$ ( 800 $\mathrm{kPa})$ in Subunit $1 \mathrm{a} ; 160 \mathrm{~m}(780 \mathrm{kPa})$ in $1 \mathrm{~b}$; and $320 \mathrm{~m}$ $(1650 \mathrm{kPa})$ in 1c. Deviations from these values can indicate the resistance of the sediment to compaction; higher (lower) void ratio values correspond to less (more) compressible sediment sections. This can be shown best for Subunit $1 \mathrm{~b}$; its sediments seem to be less compressible in this pressure range $(200-800 \mathrm{kPa})$ than do sediments from Subunits 1a and 1c. This is in accordance with observations by Hamilton (1976) on similar pelagic sediments.

In addition to the volumetric aspect of shrinkage, sediments can be characterized by linear shrinkage val-

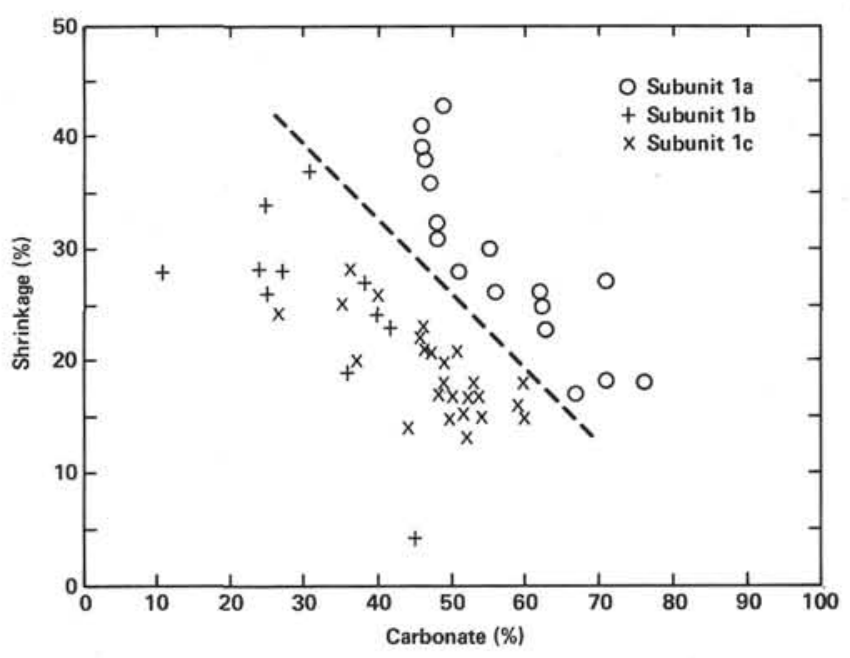

Figure 3. Relationship between shrinkage and content and type of carbonate. The dotted line divides foraminifer-rich sediments (above) from those with coccoliths as the major carbonate constituent (below). Additionally, at the same carbonate content, shrinkage decreases with increasing burial depth within each lithologic subunit.

ues in a vertical and horizontal direction. Thus, shrinkage anisotropy $\left(S h_{a}\right)$ is introduced as:

$$
S h_{a}=\frac{S h_{v}}{S h_{v}+S h_{h}} \times 100,
$$

where $S h_{v}$ refers to loss of (vertical) height and $S h_{h}$ to loss parallel to the bedding ( $\%$ of the cylinder measurements) during drying. It has been found that homogeneous sediments normally shrank isotropically $\left(S h_{a} \leq 50\right)$, whereas anisotropic shrinkage is related to sediments whose pores are not randomly oriented or formed (Fig. 6). Thus, shrinkage anisotropy depends on both the microstructure and microfabric of the sediment. This assumption is supported by observations on the shrinkage anisotropy of reference samples from laminated sediments deposited in marine euxinic environments (Baltic Sea, Sulu Sea, and overconsolidated sedimentary rocks from S.W. Germany, Fig. 6): These samples shrank anisotropically; that is, there was more shrinkage perpendicular to the bedding than parallel to it.

The influence of microstructure and microfabric was indicated by remolding of samples with anisotropic shrinking behavior and by SEM studies. Remolding is carried out in the laboratory by mixing ("homogenizing") the sample into a plastic mass at the same water content as the undisturbed sample. Remolding of a cohesive sample generally rearranges particles and disturbs the chemical equilibrium of the particles and associated absorbed ions and water molecules (Dunn et al., 1980). Thus, the bonds between particles or basic fabric entities may be destroyed (Bennett et al., 1981). After remolding, both anisotropically as well as isotropically shrinking sediments shrank isotopically. Therefore, it 


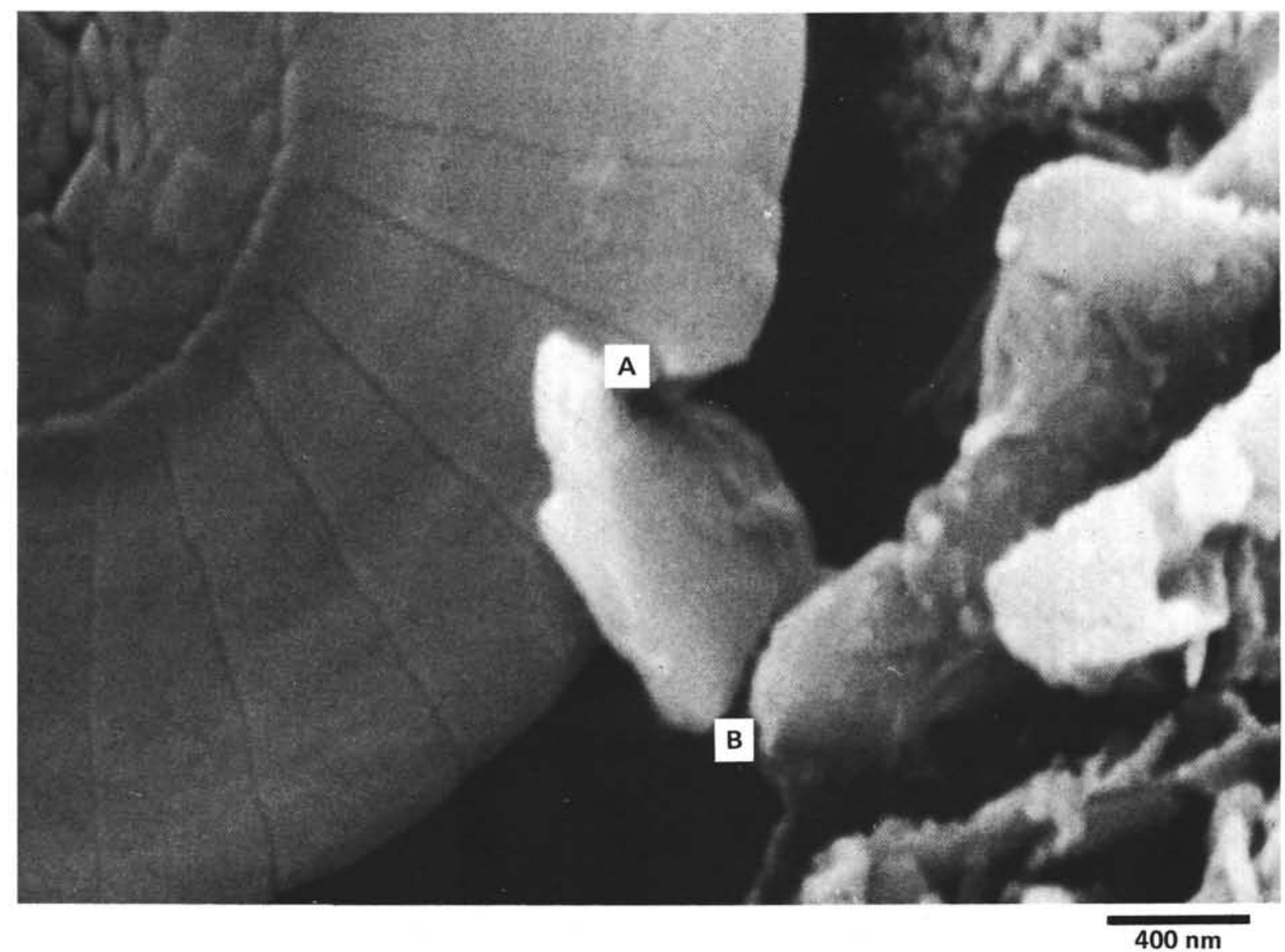

Figure 4. SEM photomicrograph (Section 12-3) illustrating structure stabilizing effect of carbonate: (A) solution feature at a coccolith and (B) carbonate precipitation stabilizing the sediment.

can be assumed that shrinkage anisotropy is related to the orientation of sediment particles, aggregates, or basic fabric entities that form the pore space. This assumption is supported by SEM observations on sediment sections with highest anisotropy of shrinkage. SEM photographs clearly reveal a preferred orientation of particles (Fig. 7). Generally, the sediment sections show a low degree of particle orientation. Highest values of shrinkage anisotropy were recognized in core sections with a low degree of bioturbation. Furthermore, sediments low in carbonate and high in clay minerals show a tendency to anisotropic shrinkage as a result of overburden, which favors orientation of clay minerals (Osipov and Sokolov, 1978a,b). On the other hand, isotropic shrinkage behavior prevails in carbonate-rich and/or coarsergrained sediments.

\section{SEDIMENT COMPOSITION AND GRAVITATIONAL COMPACTION}

The influence of sediment composition on geotechnical properties and the relationship of these to depth or effective overburden pressure can be estimated primarily in two ways: (1) evaluation of consolidation tests (see chapter by the Geotechnical Consortium, this volume) and (2) use of field data such as field compressibility (Lee, 1973). Here the latter method is used in plotting void ratio versus log of overburden pressure (Fig. 8). Thus, the volumetric response of sediments of different composition to gravitational compaction can easily be derived; in the ideal case of a uniformly composed sediment where a $\log$ scale for $p_{\text {eff }}$ is used, all plot points should fall on a straight line.

Figure 8 reflects the changing sediment composition indicated by the different gradients of void ratio versus $\log p_{\text {eff }}$ of the different lithologic subunits. The fluctuations of the major constituents within each subunit can be deduced from the scattering of data.

Subunits $1 \mathrm{a}$ and $1 \mathrm{~b}$ are strongly affected by varying amounts of major constituents. In Subunit 1a the amount of foraminiferal tests varies in the upper part, but gradually decreases in the lower part of the subunit (see also Fig. 1); in Subunit 1b the amount of diatom frustules varies widely as indicated by the scattering of data. Subunit $1 \mathrm{c}$ is less affected by changing sediment composition.

\section{CONCLUSIONS}

This study has shown that shrinkage can be measured to indicate degree of sediment compressibility. On the other hand, changing sediment composition could hardly be estimated in quantification of shrinkage. Further, the following specific observations can be made:

1) Median pore diameter decreases downhole from $0.5 \mu \mathrm{m}$ to $<0.2 \mu \mathrm{m}$ at about $200 \mathrm{~m}$ below the seafloor. These changes are strongly influenced by changing sediment composition; size as well as the contribution of the 


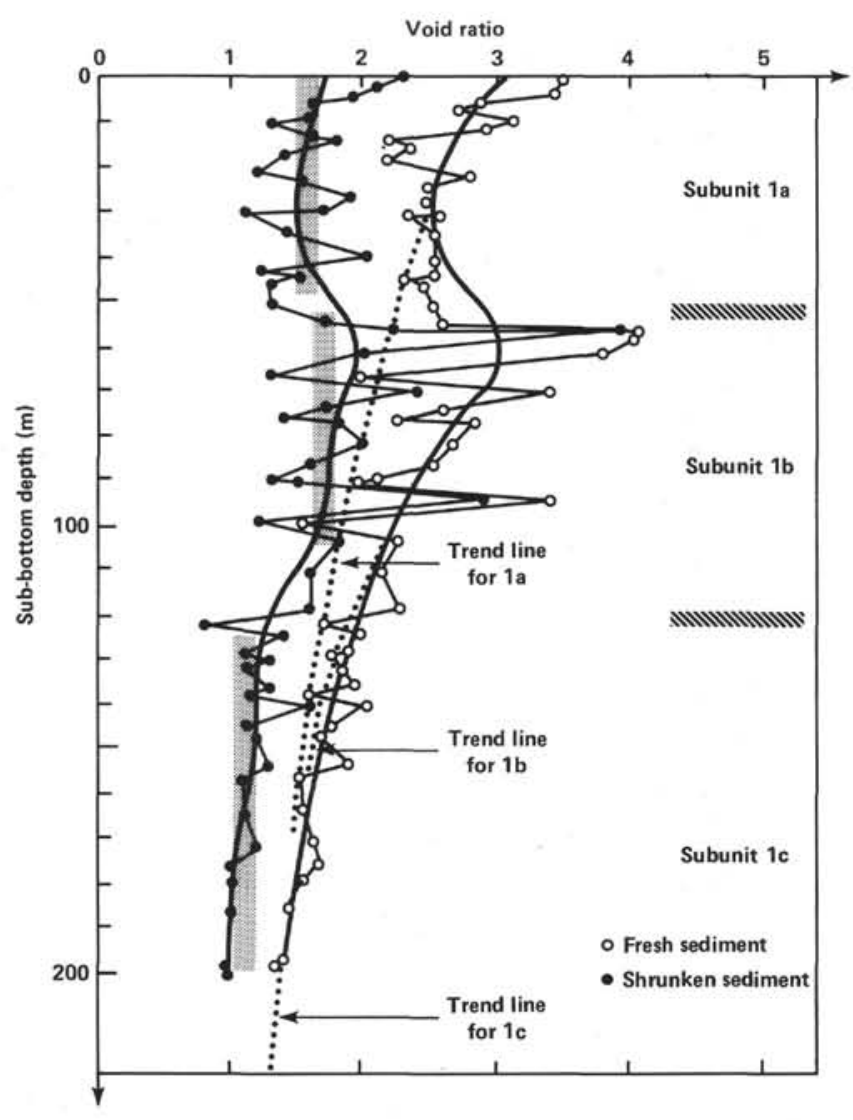

Figure 5. Void ratio of fresh and shrunken sediment samples (point plots as well as moving-average trend lines). Dotted lines have been interpolated for increasing overload. Shaded bands refer to the limiting values of void ratio within each lithologic subunit.

major biogenic constituents to the total sediment decreases within each lithologic subunit downhole: foraminifers-diatoms-coccoliths.

2) With increasing carbonate content, shrinkage decreases; further, nannofossils are more effective in stabilizing structure than are foraminifers.

3) Linear shrinkage values perpendicular and parallel to the bedding plan reveal a distinct shrinkage anisotropy. Direct (by SEM) and indirect (by remolding and reference samples) observations show that this parameter is related to orientation and geometry of pores. The degree of particle orientation varies between homogeneous and partially laminated sediments. Higher (lower) degrees of orientation have been found in sparsely (highly) bioturbated sediments and in sections low (high) in carbonate or rich in clay (coarser grained).

4) For the mean sediment composition of each lithologic subunit, the void ratios of the shrunken sediment have been related to overburden pressure: $800 \mathrm{kPa}$ (= $170 \mathrm{~m}$ ) for Subunit $1 \mathrm{a}, 780 \mathrm{kPa}(160 \mathrm{~m})$ for $1 \mathrm{~b}$, and $1650 \mathrm{kPa}(=320 \mathrm{~m})$ for $1 \mathrm{c}$. Variations from these trends can indicate sediment compressibility.

5) Void ratio versus log (overburden pressure) plots reveal a widely varying and changing sediment composition within the subunits; largest variations are in Subunit $1 \mathrm{~b}$ (diatom-rich); less exist in 1a (rich in foraminifers); and the smallest are in 1c (coccolith-rich).

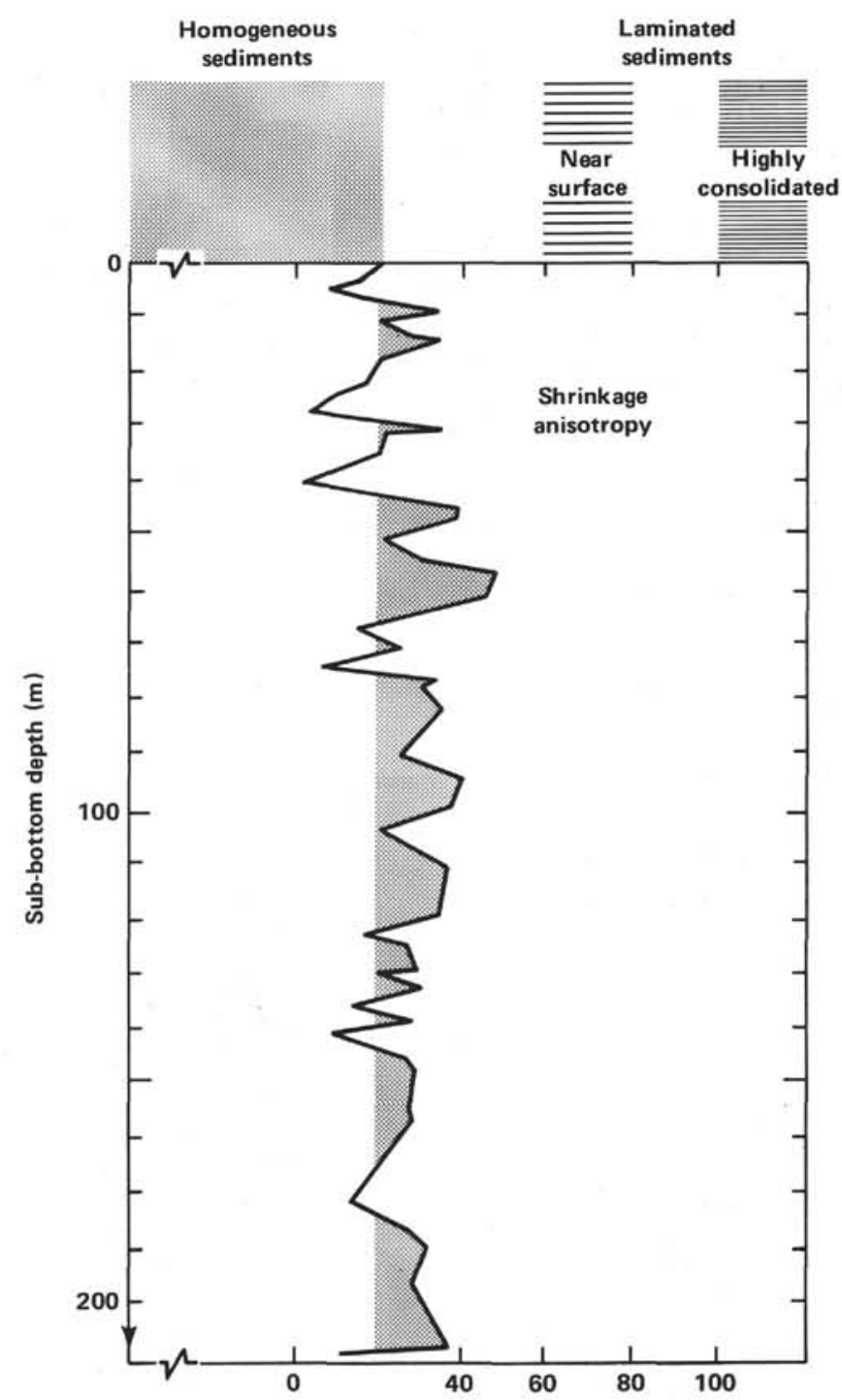

Figure 6. Shrinkage anisotropy (= vertical shrinkage/vertical + horizontal shrinkage). Above the abscissa comparisons with reference samples are made. "Homogeneous" refers to remolded sediments from the core investigated or to totally bioturbated modern sediments; laminated reference samples have been taken from modern marine near-surface sediments or highly consolidated deposits of S.W. Germany (Merklein, 1982).

\section{ACKNOWLEDGMENTS}

The author would like to thank Professor G. Einsele for suggesting this study, for stimulating discussions, and for reviewing the manuscript. Technical help was given by E. Altheimer, D. Mühlbayer, H. Hüttemann, and P. Vrbka. Dr. F. Werner (Kiel) provided reference samples from modern sediments. J. Ghiold (New York) improved the English text. Financial support was given by the DFG (Deutsche Forschungsgemeinschaft). These contributions are acknowledged with gratitude.

\section{REFERENCES}

Bennett, R. H., Bryant, W. R., and Keller, G. H., 1981. Clay fabric of selected submarine sediments: Fundamental properties and models. J. Sediment. Petrol., 51:217-232.

Brinch Hansen, J., and Lundgren, H., 1960. Hauptprobleme der Bodenmechanik: Berlin (Springer).

Dunn, I. S., Anderson, L. R., and Kiefer, F. W., 1980. Fundamentals of Geotechnical Analysis: New York, Chichester, Brisbane, Toronto (John Wiley \& Sons). 


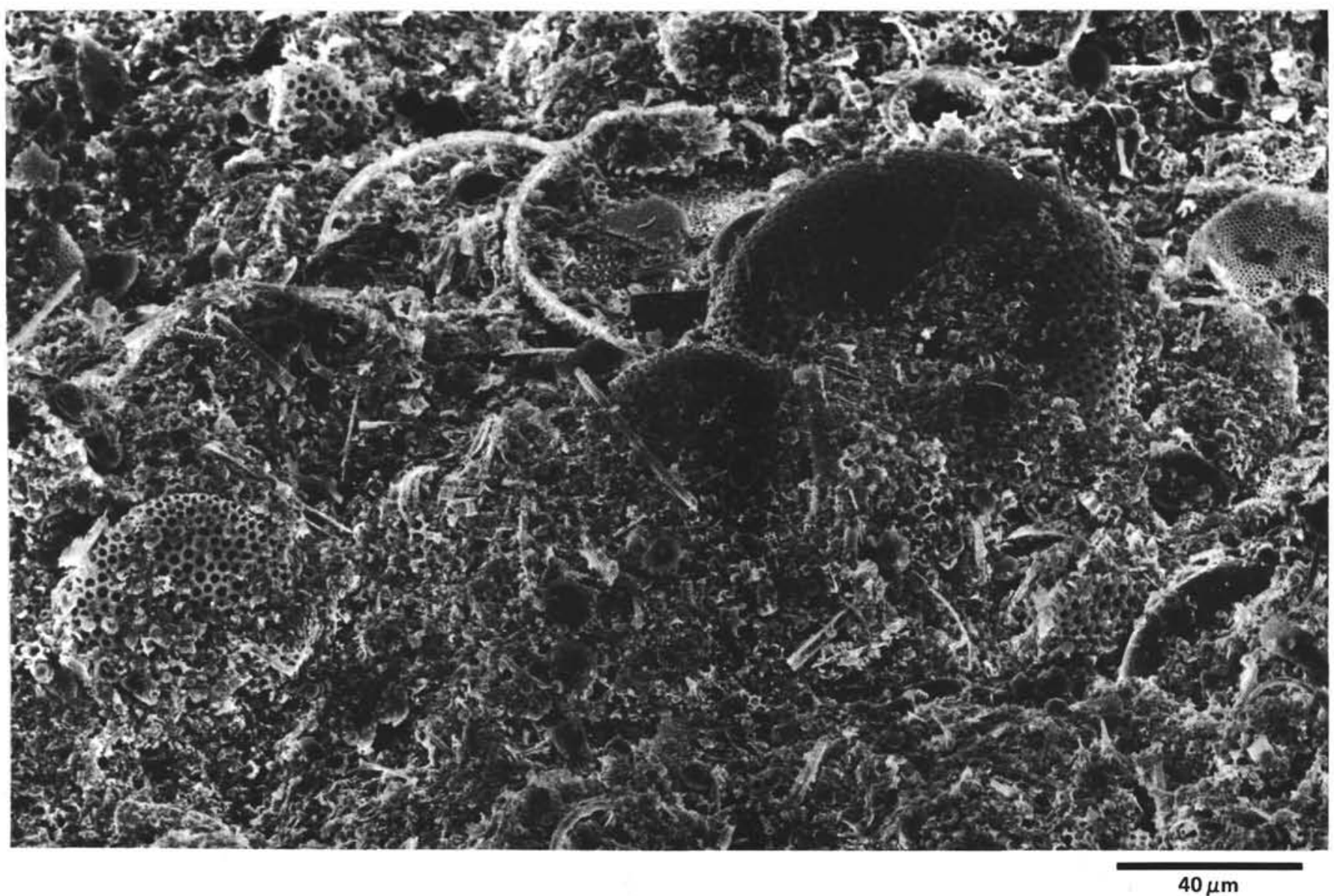

Figure 7. SEM photomicrograph of a comparatively high anisotropic shrinking sediment section (14-1); diatom frustules are oriented parallel to bedding.

Einsele, G., 1982. Mass physical properties of Pliocene to Quaternary sediments in the Gulf of California, Deep Sea Drilling Project, Leg 64: In Curray, J. R., Moore, D. G., et al., Init. Repts. DSDP, 64, Pt. 2: Washington (U.S. Govt. Printing Office), 529-543.

Hamilton, E. L., 1976. Variations of density and porosity with depth in deep-sea sediments. J. Sediment. Petrol., 46:280-300.

Hartge, K. H., 1978. Einfuhrung in die Bodenphysik: Stuttgart (Enke).

Heling, D., 1970. Micro-fabrics of shales and their rearrangement by compaction. Sedimentol., 15:247-260.

Hudec, P. P., 1978. Rock weathering on the molecular level. In Winkler, E. M., (Ed.), Decay and Preservation of Stone: Washington (Geological Soc. Am., Engineering Geology Case Histories, No. 11), 47-51.

Lee, H. J., 1973. Measurements and estimates of engineering and other physical properties, Leg 19. In Creager, J. S., Scholl, D. W., et al., Init. Repts. DSDP, 19: Washington (U.S. Govt. Printing Office), 897-901.

Lippmann, F., 1953. Die Methoden der Korngroßenanalyse bei Ziegeltonen und die Darstellung ihrer Ergebnisse. Die Ziegelindustrie, 6:44-49.
Merklein, I., 1982. Limitierende Faktoren des Trocknungs-Befeuchtungszerfalls überkonsolidierter Tonsteine. [Ph.D. thesis.]. University of Tübingen, West Germany.

Osipov, V. I., and Sokolov, V. N., 1978a. Relation between the microfabric of clay soils and their origin and degree of compaction. Bull. Int. Assoc. Engineering Geol., 18:73-81.

1978b. Structure formation in clay sediments. Bull. Int. Assoc. Engineering Geol., 18:83-90.

Pusch, R., 1973. Influence of organic matter on the geotechnical properties of clays. Natl. Swedish Bldg. Res. Doc., 11:1-64.

Reimers, C. E., 1982. Organic matter in anoxic sediments off Central Peru: Relations of porosity, microbial decomposition and deformation properties. Mar. Geol., 46:175-197.

Schachtschabel, P., Blume, H.-P., Hartge, K. H., and Schwertmann, U., 1976. Lehrbuch der Bodenkunde (69th Ed.): Stuttgart (Enke).

Schultze, E., and Muhs, H., 1967. Bodenuntersuchungen für Ingenieurbauten, 2nd Ed.: Berlin, Heidelberg, New York (Springer).

Date of Initial Receipt: December 20, 1982 
A. WETZEL

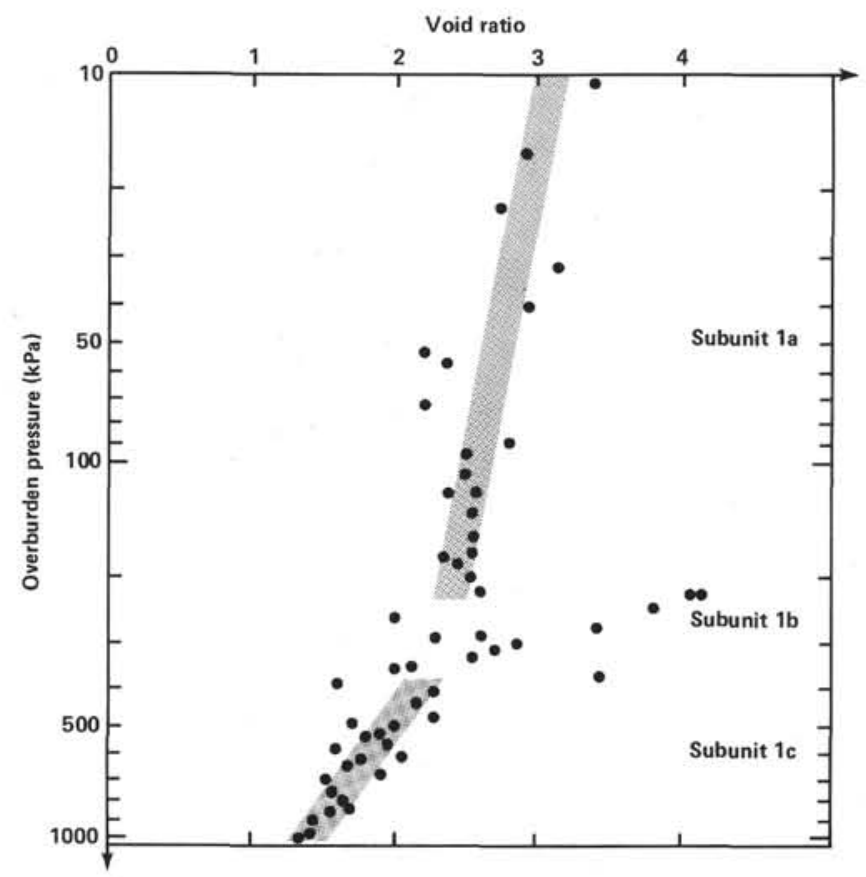

Figure 8. Sedimentation-compression curve (field compressibility) of Hole 532A. Shaded bands represent mean value lines; various inclinations refer to changes of the sediment composition of the subunits: 1a (foraminifer-rich), $1 \mathrm{~b}$ (diatom-rich), and 1c (coccolithrich). Scattering of data results from variations in sediment composition. 